\title{
Control of hysteretic sorption of flexible MOF for practical acetylene safe storage
}

\section{Mickaele Bonneau}

Kyoto University

Christophe Lavenn

Air Liquide Laboratories

Kunihisa Sugimoto

Kyoto University

Alexandre Legrand

Kyoto University

\section{Tomofumi Ogawa}

Air Liquide Laboratories

François-Xavier Coudert

Chimie ParisTech, PSL University, CNRS, Institut de Recherche de Chimie Paris, 75005 Paris, France https://orcid.org/0000-0001-5318-3910

\section{Regis Réau}

Air Liquide R\&D, Innovation Campus Paris

\section{Ken-ichi Otake}

Kyoto University

Susumu Kitagawa ( $\sim$ kitagawa@icems.kyoto-u.ac.jp )

Kyoto University https://orcid.org/0000-0001-6956-9543

\section{Article}

Keywords: Explosive Gas Management and Storage, Pressure Range of Gas Introduction and Release, Gated Adsorption and Desorption

Posted Date: November 18th, 2020

DOl: https://doi.org/10.21203/rs.3.rs-102861/v1

License: (c) (1) This work is licensed under a Creative Commons Attribution 4.0 International License. Read Full License 


\section{Control of hysteretic sorption of flexible MOF for practical}

\section{acetylene safe storage}

Mickaele Bonneau $^{1}$, Christophe Lavenn ${ }^{2}$, Kunihisa Sugimoto ${ }^{1,3}$, Alexandre Legrand ${ }^{1}$, Tomofumi Ogawa $^{2}$, Francois-Xavier Coudert ${ }^{4}$, Regis Reau, ${ }^{5}$ Ken-ichi Otake ${ }^{1} \&$ Susumu Kitagawa $^{1 *}$

1 Institute for Integrated Cell-Material Sciences (WPI-iCeMS), Kyoto University, Sakyo-ku, Kyoto 606- 8501, Japan

2 Air Liquide Laboratories, Innovation campus Tokyo, 2-2 Hikarinooka, Yokosuka, Kanagawa, 239-0847 Japan

3 Japan Synchrotron Radiation Research Institute/ SPring-8, Kouto, Sayo, Hyogo 679-5198, Japan

4 Chimie ParisTech, PSL University, CNRS, Institut de Recherche de Chimie Paris, 75005 Paris, France

5 Air Liquide R\&D, Innovation Campus Paris 1, Chemin de la Porte des Loges 78350 Les Logesen-Josas, France.

$\overline{\text { ABSTRACT. Safe managing and storage of explosive gas, such as acetylene, is essential for }}$ industries. The practical pressure and temperature regime is quite narrow for acetylene, and the optimization by complete release of saturated gas remains challenging to control. Here, a novel approach to narrow the pressure range of gas introduction and release for the storage of unstable and pressure-sensitive gas substance is reported. Flexible metal-organic frameworks (MOFs) are expected to be an excellent storage adsorbent owing to their gated adsorption/desorption behavior. However, developing such a system in a practical and narrow pressure range remains difficult. Here, we demonstrate that the gate-opening and closing pressures of a solid solution type based on interpenetrated MOF-508 can be optimized by tuning the deformation energy of the framework and the energy of host-guest interactions. These energies were adjusted by changing the functional 
group on the MOF ligands and its ratio in the mixed-ligand system. The filling and release of acetylene in the practical pressure regions of up to $180 \mathrm{kPa}$ leads to an on-demand porous material for acetylene storage with an usable volumetric capacity of $106 \mathrm{v} / \mathrm{v}$ under mild temperature (273$298 \mathrm{~K})$ and pressure $(70-120 \mathrm{kPa})$.

The development of new technologies for efficient gas storage at ambient pressure can provide improved safety and new possibilities in terms of gas cylinder design for gas supply industries. The usable gas capacity under mild pressure and temperature conditions, which often differs from the maximum quantity adsorbed, is another concern for researchers. As a potential solution, porous materials and, in particular, metal-organic frameworks (MOFs) or porous coordination polymers (PCPs) possess inherent voids, which allow to store and deliver large amounts of gases. ${ }^{1-3}$ However, rigid MOF materials, with a Langmuir type I isotherm, exhibit close adsorption and desorption pressures, which result in a low usable capacity (Fig. 1). In contrast, flexible-type MOFs, which are called soft porous crystals (SPCs), possess both ordered network and structural transformability, which provide them higher usable capacity. ${ }^{4,5}$ Indeed, the flexibility of SPCs allows to distinguish filling from release pressures, which results in an isotherm with a sigmoidal shape characterized by a hysteresis $(\Delta)$ between the gate-opening pressure $\left(P_{\mathrm{go}}\right)$ and desorption completion (gate closing) pressure $\left(P_{\mathrm{gc}}\right)$, with $\Delta=P_{\mathrm{go}}-P_{\mathrm{gc}}\left(\right.$ Fig. 1). ${ }^{6}$

Although many SPCs have been synthesized and S-shaped adsorption curves have been reported, the main focus was the discovery and understanding of phenomena rather than their practical applications. Indeed, to control the adsorption properties of SPCs, different strategies have been reported to tune the parameters responsible for structural flexibility. ${ }^{7,8}$ The latter depends not only on the binding capacity and mobility of unit ligand and metal ion but also on factors such as the 
deformation of the entire framework owing to the accommodation of guest molecules in the pores. ${ }^{9}$ Even if strategies using ligand functionalization have been reported to investigate the properties of flexible MOFs, their use for the rational control over the gate-opening and closing pressure remains challenging. ${ }^{10-13}$ Therefore, a novel approach for gas storage is required with a narrow pressure range of gas introduction and release and with a low pressure limit for pressure-sensitive unstable gas substance.

Here, we chose $\left[\mathrm{Zn}_{2}(\mathrm{bdc})_{2}\left(4,4^{\prime}\right.\right.$-bpy) $]$ (bdc = 1,4-benzenedicarboxylic acid; 4,4'-bpy = 4,4'bipyridine) (MOF-508) as a candidate owing to its relative displacement of mutually interpenetrating frameworks and overall crystal softness. The gate opening and closing, which results in acetylene sorption, was successfully tuned for storage application. The introduction of a different ratio of functionalized bdc-X linkers $\left(\mathbf{X}=-\mathbf{N O}_{2}\right.$ or $\left.-\mathbf{N H}_{2}\right)$ modulates the uptake and release pressures of various gases at different temperatures while keeping a similar uptake capacity. The variation in the gate-opening pressure is explained in detail, accurately predicted within isostructural mixed-ligand MOFs, and is attributed to the interplay between frameworkframework and framework-guest interactions. To understand the outcome of affinity and steric effect of the ligand substituent, in-situ PXRD measurements combined with synchrotron powder X-ray diffractions and thermodynamic calculations were performed to provide insight on the mechanism behind the gate-opening pressure modulation. The ability to finely tune the loading and release pressures was demonstrated on acetylene as a case study of direct applicability for the industry. Indeed, owing to its explosive nature, acetylene is typically stored in an adsorbent filler combined with a solvent to improve safety (pressure limit of 2 bar). ${ }^{14-16}$ Creating a material that can store enough acetylene in this very narrow pressure range is challenging $(70-160 \mathrm{kPa})$. Up to now, only a few studies on acetylene gas storage using SPC materials have been 
conducted. This gas uptake and release pressure control strategy is applicable for well-adapted gas storage containers.
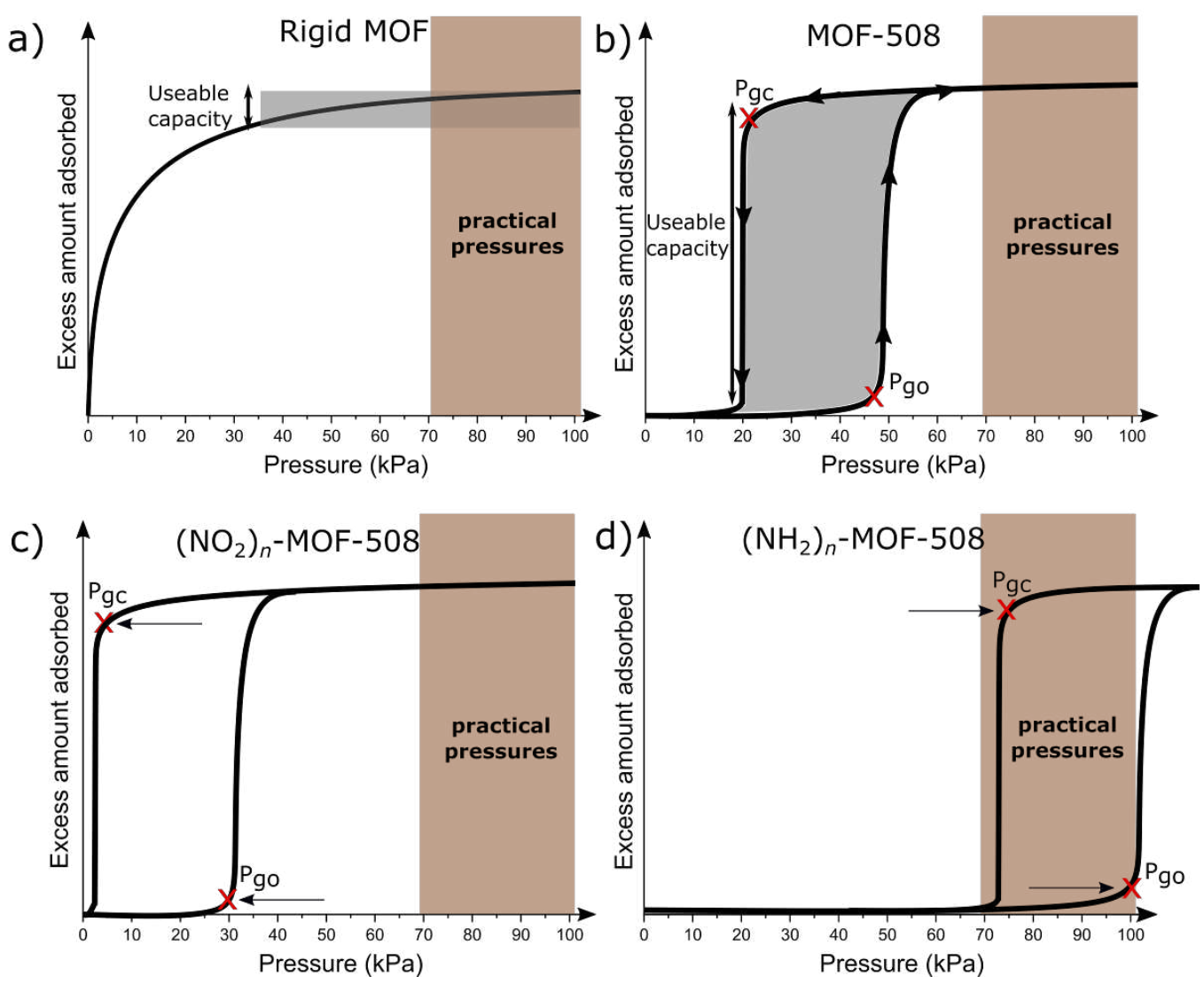

Fig. 1 | Comparison of acetylene gas sorption profiles and usable capacity in the pressure range of 0-100 $\mathrm{kPa}$ for a) a rigid material showing a type I Langmuir isotherm, b) flexible interdigitated MOF-508 showing a $S$-shape isotherm with a gate-opening pressure $\left(P_{g o}\right)$ and a gate closing pressure $\left(P_{g c}\right)$. The orange area represents the targeted mild condition range $(70-120 \mathrm{kPa})$ for acetylene uses. The functionalization of MOF-508 with $-\mathrm{NO}_{2}$ or $-\mathbf{N H}_{2}$ leads to a shift in the gate pressure to c) lower pressure or d) higher pressure range, respectively. 


\section{Results}

\section{Synthesis and characterization}

A series of MOF-508 derivatives composed of a mixture of bdc and a substituted bdc-X (with $\mathbf{X}$ $=-\mathbf{N O}_{2}$ or $-\mathbf{N H}_{2}$ ) ligand were synthesized with a precise control of the bdc/bdc-X ratio (Figs. 2a-c and Supplementary Fig. 1). ${ }^{17}$ The final linker ratio of these $\left[\mathbf{Z n}_{\mathbf{2}}(\mathbf{b d c})_{\mathbf{2}-\mathbf{a}}(\mathbf{b d c}-\mathbf{X})_{\mathbf{a}}(\mathbf{b p y})\right]$ materials (with a varying from 0 to 2 ) was confirmed by ${ }^{1} \mathrm{H}$ NMR and showed almost no deviation from the linker ratio expected from the introduced mixture (Fig. $2 \mathrm{~d}$ and Supplementary Figs. 2-14). For clarity, the samples are designated according to the function moiety ( $\mathbf{X}=-\mathbf{N H}_{2}$, $\left.-\mathbf{N O}_{2}\right)$ and molar percent $(\boldsymbol{n}=0 \%$ to $100 \%)$ as follows, $(\mathbf{X})_{n}$-MOF-508. All materials are thermally stable up to $350^{\circ} \mathrm{C}$, as observed by thermogravimetric analysis (TGA) (Supplementary Figs. 15-17). Next, the SEM images of as-synthesized samples show good homogeneity of crystallite sizes, which are in the micrometer range (Supplementary Figs. 18-19). Powder X-ray patterns, infrared analysis, and crystal structures of as-synthesized and activated samples confirmed the purity of all materials as well as their isostructural structures (Supplementary Figs. 20-26 and Tables 1-2).

Interpenetrated MOF-508 shows a dynamic transition from close (when the structure is completely evacuated from guests) to open form (when a specific gas pressure or temperature is applied). ${ }^{18}$ Thus, gas sorption properties of $(\mathbf{X})_{n}$-MOF-508 series were investigated. 
First, $(\mathbf{X})_{n}$-MOF-508 samples were confirmed to behave as a solid solution, i.e., that the ligands are homogeneously distributed within the backbone structures (Supplementary Fig. 27). ${ }^{19,20}$ The influence of the ratio of linker mixture on the gate-opening $\left(P_{g o}\right) /$ closing $\left(P_{g c}\right)$ pressures was determined from single gas adsorption measurements performed at different temperatures and pressures (Fig. 3 and Supplementary Figs. 28-35). Acetylene physisorption of pristine MOF-508 at $273 \mathrm{~K}$ shows $P_{g o}=44 \mathrm{kPa}$ and $P_{g c}=19 \mathrm{kPa}$ with an excess amount of $2.87 \mathrm{~mol} \cdot \mathrm{mol}^{-1}$ of acetylene adsorbed (Fig. 3). ${ }^{18}$ When $\left(\mathbf{N H}_{2}\right)_{n}$-MOF-508 is used, a shift in $P_{g o}$ from $48 \mathrm{kPa}$ to $83 \mathrm{kPa}$ was observed when $n$ increased from 5\% to 60\% (Fig. 3a). In contrast, for $\left(\mathbf{N O}_{2}\right)_{n}$-MOF-508, the gateopening pressure shifted to a lower pressure when $n$ increased from $5 \%$ to $100 \%$ (from $P_{g o}=31$ $\mathrm{kPa}$ to $\left.P_{g o}=1 \mathrm{kPa}\right)($ Fig. $3 \mathrm{~b})$. The plot of the gate-opening and closing pressures as a function of molar percentage of amino groups in $\left(\mathbf{N H}_{2}\right)_{n}$-MOF-508 suggests that $P_{g o}$ increases exponentially
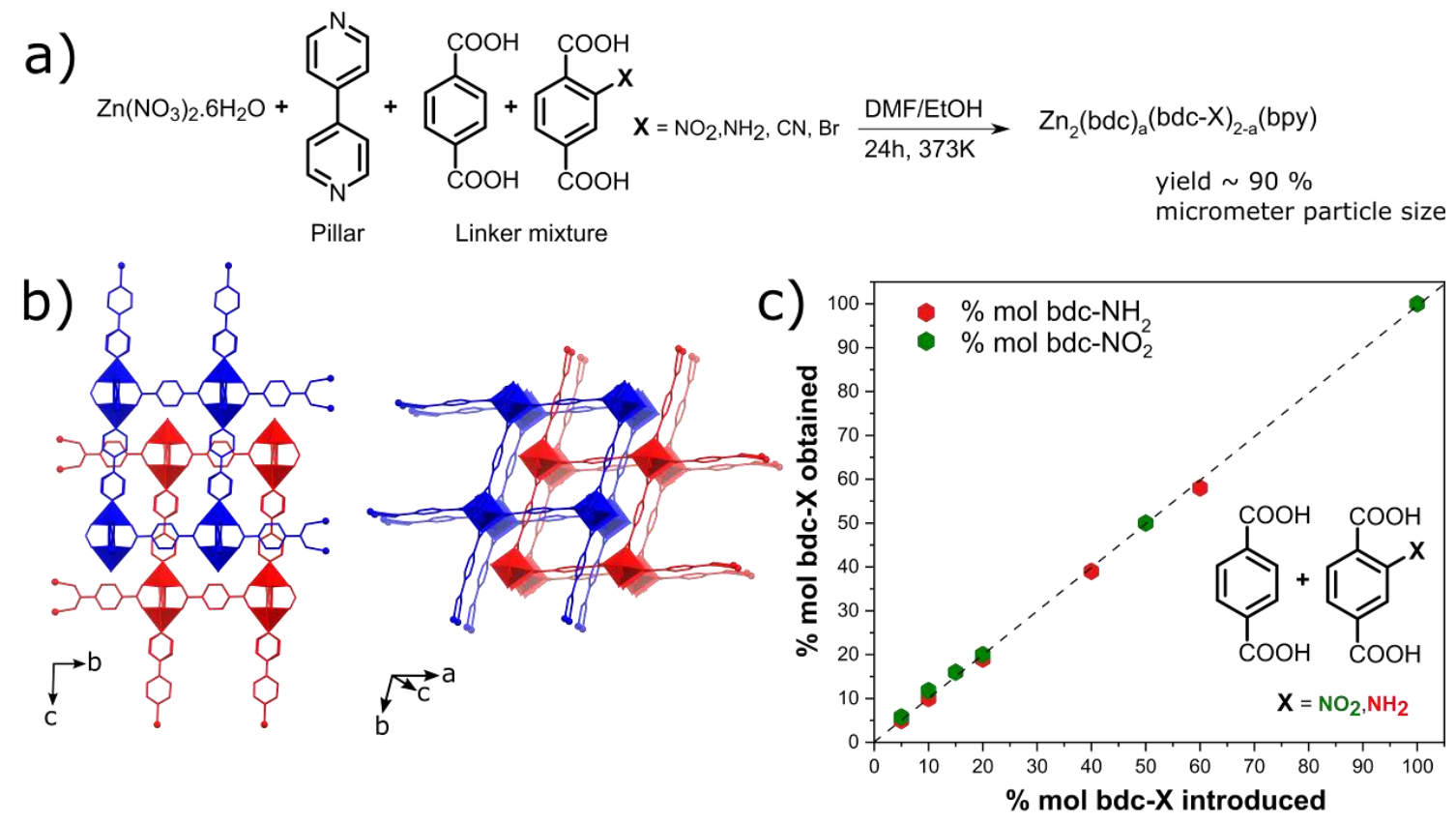

Fig. 2 | a) Synthetic scheme of (X) $)_{n}$-MOF-508 materials. b) (Left) crystal structure of activated MOF-508 along the $b$ axis and (right) crystal structure of activated MOF-508 along the $c$ axis showing a pillar ligand connecting the 2D layers. c) Molar percentage of the bdc-X linker within the material obtained as a function of the molar percentage of bdc-X introduced in the reaction. The obtained ratio was estimated from the ${ }^{1} \mathrm{HNMR}$ spectra of digested sample. 
with the amount of bdc- $\mathbf{N H}_{2}$ incorporated (Fig. 3c). At a higher molar percentage $(n>60 \%)$ of bdc- $\mathrm{NH}_{2}, P_{g o}$ is not observed below $100 \mathrm{kPa}$; however, the value can be extrapolated from the exponential fit of the lower molar percentage data points and later confirmed by the high pressure measurements (Fig. 3 and Supplementary Figs. 38-42). This extrapolation is possible because the same exponential trend is observed at a lower temperature $(195 \mathrm{~K})$ where all $P_{g o}$ values can be determined even for high amino loading (Supplementary Figs. 28-29). Additionally, the introduction of nitro moiety shows a more substantial impact on the shift of the gate-opening pressure with a more pronounced exponential decay of $P_{g o}($ Fig. 3d).

To rationalize the nature of the impact of linker substitution on the thermodynamics of the gateopening process, we applied theoretical thermodynamic models for the adsorption of guest molecules in flexible nanoporous materials to the adsorption isotherms of MOF-508 and its derivatives. ${ }^{21,22}$ Researchers previously showed that a simple two-phase model provides a good description of gate opening in interpenetrated frameworks, where gate opening is an adsorptiondriven first-order phase transition from a nonporous phase to a microporous phase. Here, we described the "open phase" adsorption by Langmuir-type fits of isotherms for all materials at 273 K. Based on the adsorption and desorption isotherms, we can calculate the value of free energy difference $\Delta F$ associated with the gate-opening process (see Supplementary Information for the equations).

First, we show that MOF-508 exhibits a relatively small free energy difference $(\Delta F=5.2 \mathrm{~kJ} / \mathrm{mol})$ between the two phases (here, all energies are reported per unit cell). This value is slightly larger, but of a similar order of magnitude, than those of other gate-opening materials (e.g., $\left[\mathrm{Cu}\left(4,4^{\prime}-\right.\right.$ bpy)(dhbc $\left.)_{2}\right] \mathrm{H}_{2} \mathrm{O}$ has $\left.\Delta F \sim 4 \mathrm{~kJ} / \mathrm{mol}\right){ }^{21,23}$ Next, the relatively small free energy difference between the two phases explains why the material readily opens upon adsorption of small guests. 
Secondly, we see that both the introduction of $-\mathbf{N O}_{2}$ and $-\mathbf{N H}_{2}$ substituents leads to a decrease in $\Delta F$ (see Supplementary Table 3 ). The impact of $-\mathbf{N H}_{2}$ is determined to be smaller than that of NO2. The presence of nitro groups decreases the free energy difference between the closed and open phases because of the steric hindrance in the closed phase. Owing to a smaller energetic cost for gate opening, opening is easier and occurs at lower gas pressure. This is particularly noticeable in the $\left(\mathrm{NO}_{2}\right)_{100}$-MOF-508 phase, where the free energy difference is almost zero, which means that the material is truly bistable, and the gate-opening transition is triggered by minute amounts of adsorbate.

In the presence of $-\mathbf{N H}_{2}$ groups, the observed effect is more complex. The introduction of $-\mathbf{N H}_{2}$ groups in MOF-508 decreases $\Delta F$, but it does not lead to a decrease in gate opening (and gate closing) pressure. This effect is smaller than for $-\mathbf{N O}_{2}$ groups because $-\mathbf{N H}_{2}$ is a less bulky substituent. Therefore, change in $\Delta F$ is not the dominant factor, and the driving force in this case is the evolution of affinity in the open phase, measured by the Henry constant $K$, which is related to the adsorption enthalpy $\Delta H$ as $K \propto \exp (-\Delta H / R T)$. When $-\mathbf{N H} 2$ groups are introduced, the surface area of the open phase is reduced, and with it, the affinity for the guest is also reduced ( $K$ decreases). In turn, lower host-guest affinity (weaker interaction) means that it takes a higher pressure for the gas to effectively adsorb, and therefore to trigger gate opening. This explains the counterintuitive experimental observations, i.e., that the introduction of $-\mathbf{N H}_{2}$ groups leads to an increase in gating pressure, while $-\mathbf{N O}_{2}$ groups lead to a decrease in gating pressure. Finally, thermodynamic models also explain why the evolution of gate-opening pressure exhibits an exponential dependency on the composition of MOF ligands. In a gate-opening material, the transition pressure is determined at thermodynamic equilibrium by the following: 


$$
P_{\mathrm{go}}=\frac{N}{K}\left(e^{-\frac{\Delta F}{N R T}}-1\right)=\frac{N}{K_{0}} e^{\frac{\Delta H}{R T}}\left(e^{-\frac{\Delta F}{N R T}}-1\right)
$$

where $N$ is the saturation uptake in the open phase; $K$ is the Henry constant; $\Delta H$ is the adsorption enthalpy, and $\Delta F$ is the free energy difference between the phases. While the general expression
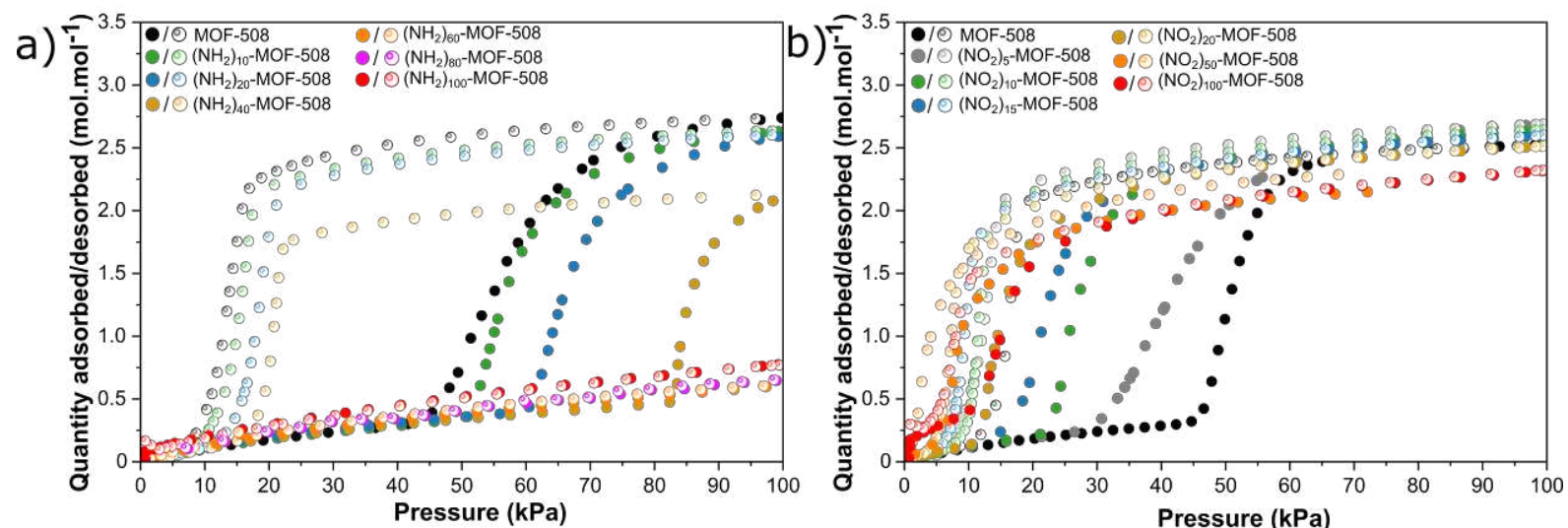

c)

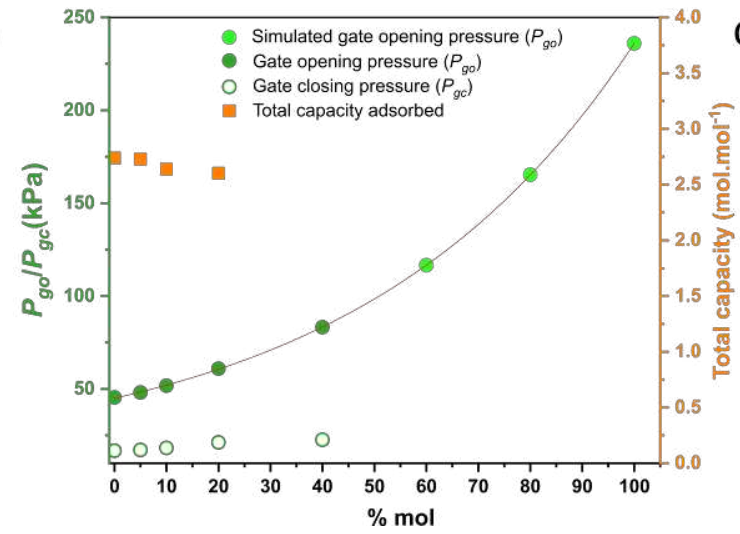

d)

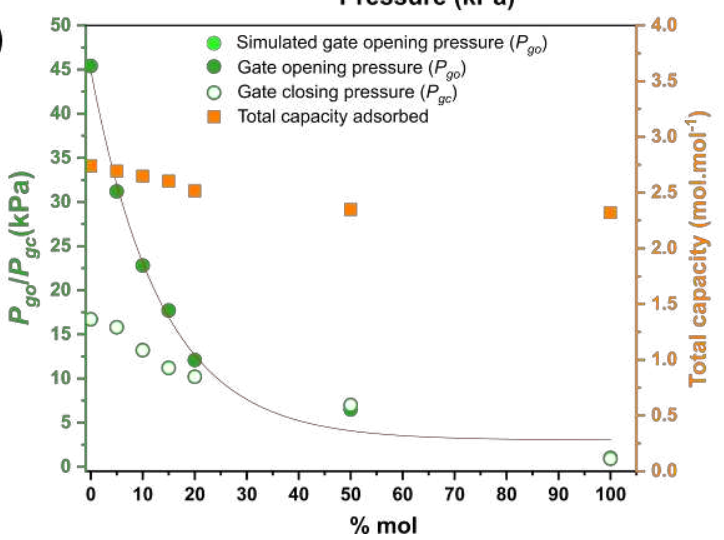

Fig. 3 a) Acetylene $\left(\mathrm{C}_{2} \mathrm{H}_{2}\right)$ adsorption isotherms for all $\left(\mathbf{N H}_{2}\right)_{n}-\mathbf{M O F}-508$ at $273 \mathrm{~K}$. The MOF-508 isotherm (black) was added for comparison. b) Acetylene $\left(\mathrm{C}_{2} \mathrm{H}_{2}\right)$ adsorption isotherms for all (NO2) $)_{n}$-MOF-508 at $273 \mathrm{~K}$. The MOF-508 isotherm (black) was added for comparison. c) Acetylene $\left(\mathrm{C}_{2} \mathrm{H}_{2}\right)$ gate opening (green filled circle), predicted gate opening (light green filled circle) and closing (green empty circle) pressure for all $\left(\mathbf{N H}_{2}\right)_{n}$-MOF-508 at $273 \mathrm{~K}$. Total capacity (orange filled square) as a function of mol\% of $-\mathbf{N H}_{2}$ in MOF-508 if reached below $100 \mathrm{kPa}$. d) Acetylene $\left(\mathrm{C}_{2} \mathrm{H}_{2}\right)$ gate opening (green filled circle) and closing (green, empty circle) pressure for all $\left(\mathbf{N O}_{2}\right)_{n}-\mathbf{M O F}-508$ at $273 \mathrm{~K}$. Total capacity (orange filled square) as a function of mol\% of -NO2 in MOF-508 if reached below $100 \mathrm{kPa}$.

is complex, in the case of the MOF-508 materials, the variation in $N$ is marginal, and the gate- 
opening pressure is controlled by the exponential dependence on both host property $(\Delta F)$ and hostguest interaction $(\Delta H)$; both quantities vary linearly with the linker composition.

These results suggest the possibility to rationally control the gate-opening and closing pressure by introducing a different ratio of functional groups. Additionally, the dependence of gate-opening and closing on the observed molar ratio of amino or nitro functional groups is not unique to acetylene but also occurs for $\mathrm{CO}_{2}, \mathrm{O}_{2}$, and $\mathrm{CH}_{4}$, which demonstrates the versatility of the method (Supplementary Figs. 30-35).

Of note, the total adsorbed capacity does not considerably change for all $\left(\mathbf{N H}_{2}\right)_{n}$-MOF-508 compared to that for pristine MOF-508 for acetylene gas at $273 \mathrm{~K}$ (Fig. 3c). The total adsorbed capacity at higher loading in the ( $\left.\mathbf{N H}_{2}\right)_{n}$-MOF-508 series was recorded at a lower temperature ( $\mathrm{T}$ $=195 \mathrm{~K})$, and it demonstrated that the total capacity did not decrease for all $\left(\mathbf{N H}_{2}\right)_{n}$-MOF-508 series (Supplementary Fig. 28-29). Conversely, the capacity decreases up to $15 \%$ for $\left(\mathbf{N O}_{2}\right)_{100-}$ MOF-508 (from 2.73 mol.mol ${ }^{-1}$ to $2.32 \mathrm{~mol}^{\mathrm{mol}}{ }^{-1}$ ). This difference is expected owing to the bulkier nitro moiety (VDW surface area bdc-NO $\mathrm{NO}_{2}=249.2 \AA$ ) compared to the amino one (VDW surface area bdc- $\mathrm{NH}_{2}=223.3 \AA$ ).

\section{In-situ PXRD}

To further investigate the effect of substituted-bdc, the phase transformation of the structure was also characterized for MOF-508, $\left(\mathrm{NH}_{2}\right)_{100}-\mathrm{MOF}-508$, and $\left(\mathrm{NO}_{2}\right)_{100}-\mathrm{MOF}-508$ by in-situ PXRD under various acetylene pressures at $195 \mathrm{~K}$ (Supplementary Fig. 36).

Increasing gas pressure leads to the transition from close to open phase structure, which occurs at different pressures for the three samples. The gate-opening pressures, which correspond to the phase transition observed on the PXRD patterns, are observed at $P_{g o}=0.04,0.21$, and $1.16 \mathrm{kPa}$ for 
$\left(\mathrm{NO}_{2}\right)_{100}$-MOF-508, MOF-508, and $\left(\mathrm{NH}_{2}\right)_{100}$-MOF-508, respectively, and this difference is explained by the difference in the starting structure. At a low pressure (below $P_{\mathrm{go}}$ ), the PXRD patterns of activated MOFs (closed form) for $\left(\mathrm{NH}_{2}\right)_{100}$-MOF-508 and $\left(\mathrm{NO}_{2}\right)_{100}$-MOF-508 show a decrease and increase of the volume cell, respectively, compared to pristine MOF-508, as seen from the shift of the 100 peak. These results are confirmed by the crystal structure obtained from X-ray diffraction experiments (Supplementary Table 1-2). ${ }^{24}$ The cell volume of activated $\left(\mathbf{N O}_{2}\right)_{100}$-MOF-508 $\left(715.9 \AA^{3}\right)$ is higher compared to those of MOF-508b $\left(703.6 \AA^{3}\right)$ and $\left(\mathbf{N H}_{2}\right)_{100}$-MOF-508 $\left(701.9 \AA^{3}\right)$, which is attributed to i) the softer interaction of - $\mathbf{N O}_{2}$ groups with the metal nodes and ii) the steric hindrance of $-\mathrm{NO}_{2}$ moiety, which further separates the aromatic part of the ligand. Therefore, the stabilization of the structure through $\pi-\pi$ interactions is reduced, as observed in pristine MOF, which explains the lower observed gate-opening pressure and is supported by the decrease of the free energy when increasing the nitro content, as described above. 25

For $\left(\mathbf{N H}_{2}\right)_{100}$-MOF-508, the higher pressure needed for the gate opening to occur is explained from the initially more contracted structure owing to interactions between $-\mathbf{N H}_{2}$ moieties and oxygen atom from the metal paddlewheel. ${ }^{24}$ Finally, in the higher pressure range, all MOF structures are completely open, and they display similar diffraction patterns (Supplementary Figs. 36d-f). Considering that the opened and closed forms of each materials are isostructural, the difference in the gate-opening pressure is attributed to the functionalized bdc- $\mathbf{X}$ linker.

\section{Optimal conditions}

Owing to the insight on the structural dynamics of MOFs obtained from the combination of various characterization techniques, we can predict the behavior of $(\mathbf{X})_{n}$-MOF-508 materials and determine optimal conditions for acetylene adsorption/desorption. 

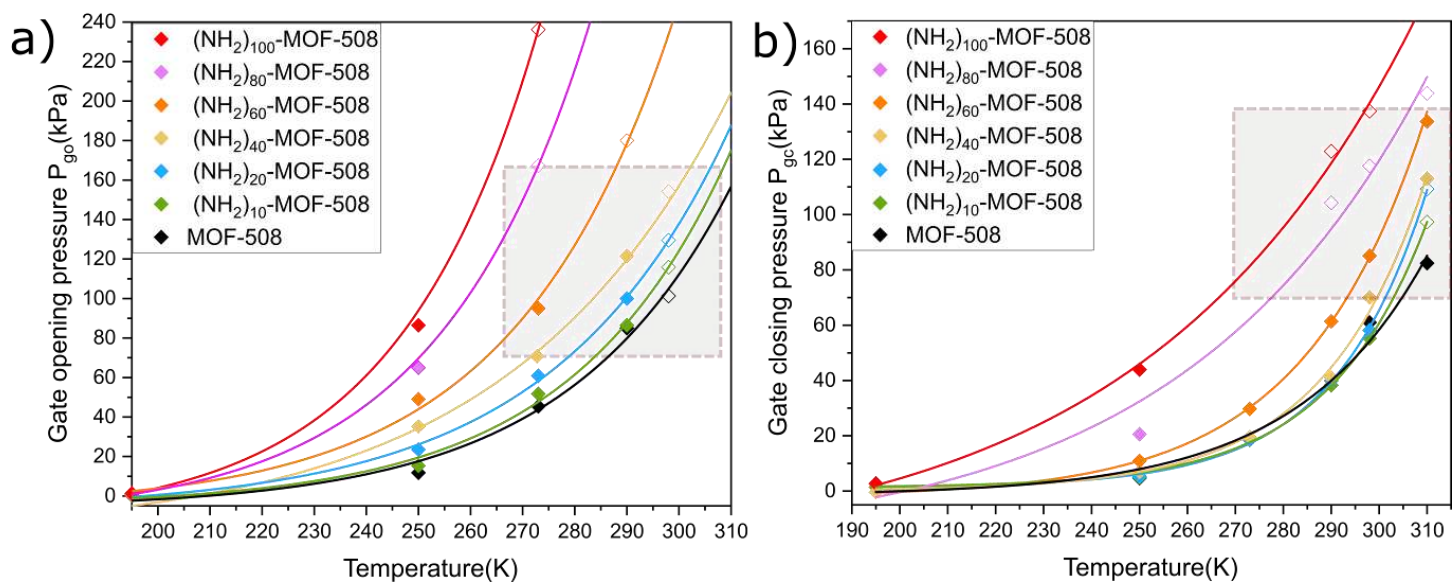

Fig. 4 | Predicted gate a) opening and b) closing pressures of MOF-508 and $\left(\mathbf{N H}_{2}\right)_{n}$-MOF-508 as a function of temperature. Gray square shows the best region for practical temperature and pressure use conditions for acetylene gas storage (temperature of 273-310 K and pressure of $70-160 \mathrm{kPa})$.

The collected measurements combined with estimated data allow us to predict gate opening and closing as a function of temperature (Fig. 4). Thus, engineering our system for the optimal temperature and pressure required for safe handling and use of acetylene gas is possible $(\mathrm{T}=273-$ $310 \mathrm{~K}$ and $\mathrm{P}=70-160 \mathrm{kPa}$, gray area, Fig. 4). In terms of the ambient condition utilization of the bottle, $\left(\mathbf{N H}_{2}\right)_{60}$-MOF-508 shows interesting results with $P_{g o}=95 \mathrm{kPa}$ at $273 \mathrm{~K}$ and $P_{g c}=91 \mathrm{kPa}$ at 298 K, which meets the practical use for safe acetylene storage (Fig. 4 and Supplementary Figs. 38-43). Furthermore, when comparing the usable volumetric capacity (UVC) of acetylene for $\left(\mathbf{N H}_{2}\right)_{60}$-MOF-508 with those of reported MOFs, the former provides an UVC of $106 \mathrm{v} / \mathrm{v}$, with complete filling at $100 \mathrm{kPa}$ and $273 \mathrm{~K}$ and $84 \%$ degassing at $70 \mathrm{kPa}$ and $298 \mathrm{~K}$, which is higher than for most reported MOFs (Supplementary Table 4 and Fig. 42). ${ }^{26-29}$ Of note, compared to all reported MOFs for acetylene storage, the MOF-508 family is the only material with gate-opening behavior and, thus, paves the way for the future development of flexible MOF for acetylene storage. In addition, recording adsorption isotherms at a higher pressure than at an ambient one was possible with a higher amino content $(x>60 \%)$, to observe complete gate-opening pressure while 
staying under the 2 bar limit pressure, which shows the potential for obtaining better UVC. This pressure range, which makes the industrial application of these MOFs possible, is unprecedented.

In summary, compared to the current solvent compression method, the use of MOF adsorbents to store acetylene exhibits practical advantages. First, high acetylene purity can be achieved because no solvents (acetone or DMF) that can degrade or contain contaminants are required. Second, avoiding flammable and harmful solvents increases safety when handling acetylene bottles. In addition, the adsorbed gas can be confined in MOF pores at a lower pressure compared to 19 bar at $20^{\circ} \mathrm{C}$ needed for the non-static solvent/porous filler storage method. Furthermore, functionalized flexible $(\mathbf{X})_{n}$-MOF-508 can compress large quantities of acetylene $(\sim 129 \mathrm{v} / \mathrm{v})$ in less than 2 bar, which allows to develop lighter gas bottle containers. Finally, the remaining unused acetylene, which requires low pressure $(<70 \mathrm{kPa})$ to be completely desorbed, presents a potential explosive risk, which can be solved by flexible MOFs. Indeed, we demonstrated the rational design of MOF whose gate-opening pressure is controlled by varying the ratio of ligand substituents. Therefore, flexible $(\mathbf{X})_{n}$-MOF-508 offers tunable uptake/release gas pressures, while being also able to fully release acetylene at an ambient pressure (storage at $273 \mathrm{~K}$ and $\mathrm{P}>2$ bar, release at $298 \mathrm{~K}$ and $\mathrm{P} \leq$ $70 \mathrm{kPa}$ ). This approach to gas storage demonstrates its practicality through the design of a narrow pressure range of gas introduction and release and with a low pressure limit for pressure-sensitive unstable gas substance.

These results open the way for the application of flexible MOF to the effective storage of targeted gases from the discovery of cooperative adsorption phenomena. 


\section{Methods}

\section{MOF synthesis}

MOF-508 and $(\mathbf{X})_{n}$-MOF-508 series $\left(\boldsymbol{n}=0 \%\right.$ to $100 \%$ and $\left.\mathbf{X}=-\mathbf{N H}_{2},-\mathbf{N O}_{2}\right)$ were prepared following the previously used method. ${ }^{17}$ 1,4-benzenedicarboxylic acid is dissolved with functionalized 1,4-benzenedicarboxylic acid (total 2 eq) in DMF (concentration [bdc linker] = $0.15 \mathrm{M})$ at $100^{\circ} \mathrm{C}$ for $15 \mathrm{~min}$. An ambient solution of $\mathrm{Zn}\left(\mathrm{NO}_{3}\right) \cdot 6 \mathrm{H}_{2} \mathrm{O}(2 \mathrm{eq})$ in $\mathrm{DMF}$ (concentration $[$ metal $]=0.4 \mathrm{M})$ was added to the stirring mixture at $100^{\circ} \mathrm{C}$ for $10 \mathrm{~min} .4,4^{\prime}$-bipyridine $(1 \mathrm{eq})$ is dissolved at room temperature in $\mathrm{EtOH}$ (concentration [pillar] $=0.1 \mathrm{M}$ ) and added to the reaction mixture. The mixture was kept at $100^{\circ} \mathrm{C}$ for $24 \mathrm{~h}$. Next, after cooling down to room temperature, the resulting precipitate was collected by centrifugation and washed three time with $\mathrm{DMF}(3 \times 40$ $\mathrm{mL})$ and three times with $\mathrm{EtOH}(3 \times 40 \mathrm{~mL})$. The white/yellow powder is dried under vacuum at $50^{\circ} \mathrm{C}$ for $12 \mathrm{~h}$.

\section{Gas sorption}

Single gas adsorption isotherms of MOF samples were previously activated through thermal activation at $423 \mathrm{~K}$ for $12 \mathrm{~h}$ before measurement. The adsorption isotherms were measured with BELSORP-CRYO $\left(\mathrm{C}_{2} \mathrm{H}_{2}\right.$ and $\left.\mathrm{CO}_{2}\right)$ and BELSORP-MAX $\left(\mathrm{C}_{2} \mathrm{H}_{2}, \mathrm{CO}_{2}, \mathrm{CH}_{4}\right.$, and $\left.\mathrm{O}_{2}\right)$ volumetric adsorption equipment from Bel Japan. Targeted relative pressures in the range of $0.01-100 \mathrm{kPa}$ were defined, and limits of excess and allowance amount were set to 5 and $10 \mathrm{~cm}^{3} \mathrm{~g}^{-1}$, respectively. The equilibration condition for each point was $0.03 \%$ pressure change within $300 \mathrm{~s}$. Finally, the dead volume was determined using helium gas.

\section{$\underline{\text { In-situ PXRD measurements }}$}


Gas sorption measurements were performed on BELSORP-18PLUS (MicrotracBEL, Japan, Corp.) automated volumetric sorption analyzers equipped with cryostat temperature controllers. The in-situ PXRD/adsorption measurements were performed using a Rigaku SmartLab (with $\mathrm{Cu}-\mathrm{K} \alpha$ radiation) connected to BELSORP-18PLUS volumetric adsorption equipment. These instruments were synchronized with each other, and each PXRD pattern was obtained at each point of sorption isotherms. Finally, the samples were previously activated through external thermal activation at $423 \mathrm{~K}$ for $12 \mathrm{~h}$ and further $2 \mathrm{~h}$ internal activation at $423 \mathrm{~K}$ before measurement.

\section{Acknowledgements}

This work was supported by Air Liquide via the 2016 Air Liquide Scientific Challenge, a KAKENHI Grant-in-Aid for Specially Promoted Research (JP25000007), Scientific Research (S) (JP18H05262), and Early-Career Scientists (JP19K15584) from the Japan Society of the Promotion of Science (JSPS). Single-crystal X-ray diffraction experiments were performed at beamline 02B1. We are grateful to CNRS-Kyoto LIA "SMOLAB". In addition, we thank Air Liquide Japan, Dr. Patrick Ginet and Laurent Prost as well as the technical staff for advices and experimental assistance

\section{Author Contributions}

M.B. S.K., C.L and R.R. formulated the project. M.B and C.L. synthesized the compounds and collected the gas adsorption data. M.B. collected and analyzed all the ${ }^{1} \mathrm{H}$ NMR data. M.B. collected all the in-situ PXRD data. M.B. and C.L analyzed all adsorption data. M.B and C.L. collected and analyzed the TGA and powder X-ray diffraction data. M.B. and K.S. collected and analyzed the single-crystal X-ray diffraction data. A.L. and M.B. collected all SEM images UV-vis and IR data. 
F-X.C. performed the thermodynamics calculations. T.O. and C.L. build and collected the sorption data from the acetylene experimental set-up. M.B with assistance from O.K-I, A.L. and F-X.C wrote the paper, and all authors contributed to revising the paper.

\section{Data availability}

Reprints and permissions information is available at www.nature.com/reprints. The authors declare competing financial interests: details are available in the online version of the paper. Crystallographic data for as-synthesized and activated $\left(\mathbf{N O}_{2}\right)_{100}-\mathbf{M O F}-508$ structures have been deposited in the Cambridge Structural Database with CCDC numbers 2036574 2036575.respectively. Readers are welcome to comment on the online version of the paper. Correspondence and requests for materials should be addressed to S.K.

\section{References}

1 Kapelewski, M. T. et al. Record High Hydrogen Storage Capacity in the Metal-Organic Framework $\mathrm{Ni2}$ (m-dobdc) at Near-Ambient Temperatures. Chem. Mater. 30, 8179-8189, doi:10.1021/acs.chemmater.8b03276 (2018).

2 Li, B., Wen, H.-M., Zhou, W., Xu, Jeff Q. \& Chen, B. Porous Metal-Organic Frameworks: Promising $\begin{array}{llll}\text { Materials for } \text { Methane Storage. Chem 1, 557-580, } & \text {, }\end{array}$ doi:https://doi.org/10.1016/j.chempr.2016.09.009 (2016).

3 Moghadam, P. Z. et al. Computer-aided discovery of a metal-organic framework with superior oxygen uptake. Nat. Commun. 9, 1378, doi:10.1038/s41467-018-03892-8 (2018).

4 Horike, S., Shimomura, S. \& Kitagawa, S. Soft porous crystals. Nat. Chem. 1, 695-704, doi:10.1038/nchem.444 (2009).

5 Warren, J. E. et al. Shape Selectivity by Guest-Driven Restructuring of a Porous Material. Angew. Chem. Int. Ed. 53, 4592-4596, doi:10.1002/anie.201307656 (2014).

6 Chang, Z., Yang, D.-H., Xu, J., Hu, T.-L. \& Bu, X.-H. Flexible Metal-Organic Frameworks: Recent Advances and Potential Applications. Adv. Mater. 27, 5432-5441, doi:10.1002/adma.201501523 (2015).

7 Mason, J. A. et al. Methane storage in flexible metal-organic frameworks with intrinsic thermal management. Nature 527, 357-361, doi:10.1038/nature15732 (2015).

8 Zhu, A.-X. et al. Tuning the Gate-Opening Pressure in a Switching pcu Coordination Network, Xpcu-5-Zn, by Pillar-Ligand Substitution. Angew. Chem. Int. Ed. 58, 18212-18217, doi:10.1002/anie.201909977 (2019). 

Crystal. J. Am. Chem. Soc. 131, 5516-5521, doi:10.1021/ja8089872 (2009).

10 Sun, $X$. et al. Tuning the gate opening pressure of a flexible doubly interpenetrated metal-organic framework through ligand functionalization. Dalt. Trans, 47, 13158-13163, doi:10.1039/C8DT02544D (2018).

11 Schwedler, I. et al. Mixed-linker solid solutions of functionalized pillared-layer MOFs - adjusting structural flexibility, gas sorption, and thermal responsiveness. Dalt. Trans, 45, 4230-4241, doi:10.1039/C5DT03825A (2016).

12 Foo, M. L., Matsuda, R. \& Kitagawa, S. Functional Hybrid Porous Coordination Polymers. Chem. Mater. 26, 310-322, doi:10.1021/cm402136z (2014).

13 Lescouet, T., Kockrick, E., Bergeret, G., Pera-Titus, M. \& Farrusseng, D. Engineering MIL-53(Al) flexibility by controlling amino tags. Dalt. Trans, 40, 11359-11361, doi:10.1039/C1DT11700A (2011).

14 Matsuda, R. et al. Highly controlled acetylene accommodation in a metal-organic microporous material. Nature 436, 238-241, doi:10.1038/nature03852 (2005).

15 Safetygram 13, Acetylene. Air Products and Chemicals Inc. ( 2014).

16 Solvents for Acetylene Filling. European Industrial Gases Association AISBL Doc. 225/19 (2019).

17 Chen, B. et al. A Microporous Metal-Organic Framework for Gas-Chromatographic Separation of Alkanes. Angew. Chem. Int. Ed. 45, 1390-1393, doi:10.1002/anie.200502844 (2006).

18 Xiang, S., Zhou, W., Gallegos, J. M., Liu, Y. \& Chen, B. Exceptionally High Acetylene Uptake in a Microporous Metal-Organic Framework with Open Metal Sites. J. Am. Chem. Soc. 131, 1241512419, doi:10.1021/ja904782h (2009).

19 Fukushima, T. et al. Modular Design of Domain Assembly in Porous Coordination Polymer Crystals via Reactivity-Directed Crystallization Process. J. Am. Chem. Soc. 134, 13341-13347, doi:10.1021/ja303588m (2012).

20 Lescouet, T. et al. Homogeneity of flexible metal-organic frameworks containing mixed linkers. J. Mater. Chem. 22, 10287-10293, doi:10.1039/C2JM15966J (2012).

21 Coudert, F.-X., Jeffroy, M., Fuchs, A. H., Boutin, A. \& Mellot-Draznieks, C. Thermodynamics of Guest-Induced Structural Transitions in Hybrid Organic-Inorganic Frameworks. Journal of the American Chemical Society 130, 14294-14302, doi:10.1021/ja805129c (2008).

22 Bousquet, D., Coudert, F. X. \& Boutin, A. Free energy landscapes for the thermodynamic understanding of adsorption-induced deformations and structural transitions in porous materials. J. Chem. Phys. 137, 044118, doi:10.1063/1.4738776 (2012).

23 Kitaura, R., Fujimoto, K., Noro, S.-i., Kondo, M. \& Kitagawa, S. A Pillared-Layer Coordination Polymer Network Displaying Hysteretic Sorption: [Cu2(pzdc)2(dpyg)]n (pzdc= Pyrazine-2,3dicarboxylate; dpyg=1,2-Di(4-pyridyl)glycol). Angew. Chem. Int. Ed. 41, 133-135, doi:10.1002/1521-3773(20020104)41:1<133::aid-anie133>3.0.co;2-r (2002).

$24 \mathrm{Gu}, \mathrm{Y}$. et al. Structural-Deformation-Energy-Modulation Strategy in a Soft Porous Coordination Polymer with an Interpenetrated Framework. Angew. Chem. Int. Ed. 59, 15517-15521, doi:10.1002/anie.202003186 (2020).

25 Ghoufi, A., Maurin, G. \& Férey, G. Physics Behind the Guest-Assisted Structural Transitions of a Porous Metal-Organic Framework Material. J. Phys. Chem. Lett. 1, 2810-2815, doi:10.1021/jz1011274 (2010).

26 He, Y., Krishna, R. \& Chen, B. Metal-organic frameworks with potential for energy-efficient adsorptive separation of light hydrocarbons. Energy Environ. Sci. 5, 9107-9120, doi:10.1039/C2EE22858K (2012). 

exhibiting high acetylene and carbon dioxide storage capacities. CrystEngComm 19, 1464-1469, doi:10.1039/C6CE02291J (2017).

28 Pang, J. et al. A porous metal-organic framework with ultrahigh acetylene uptake capacity under ambient conditions. Nat. Commun. 6, 7575, doi:10.1038/ncomms8575 (2015).

Cai, J. et al. An amino-decorated NbO-type metal-organic framework for high $\mathrm{C} 2 \mathrm{H} 2$ storage and selective CO2 capture. RSC Adv. 5, 77417-77422, doi:10.1039/C5RA12700A (2015).

\section{Figure legends}

Fig. 1 | Comparison of acetylene gas sorption profiles and usable capacity in the pressure range of 0-100 kPa for a) a rigid material showing a type I Langmuir isotherm, b) flexible interdigitated MOF-508 showing a S-shape isotherm with a gate-opening pressure $\left(P_{g o}\right)$ and a gate closing pressure $\left(P_{g c}\right)$. The orange area represents the targeted mild condition range (70-120 $\mathrm{kPa}$ ) for acetylene uses. The functionalization of MOF-508 with $-\mathbf{N O}_{2}$ or $-\mathbf{N H}_{2}$ leads to a shift in the gate pressure to c) lower pressure or d) higher pressure range, respectively.

Fig. 2 | a) Synthetic scheme of $(\mathbf{X})_{n}$-MOF-508 materials. b) (Left) crystal structure of activated MOF-508 along the $b$ axis and (right) crystal structure of activated MOF-508 along the $c$ axis showing a pillar ligand connecting the 2D layers. c) Molar percentage of the bdc-X linker within the material obtained as a function of the molar percentage of bdc-X introduced in the reaction. The obtained ratio was estimated from the ${ }^{1} \mathrm{HNMR}$ spectra of digested sample.

Fig. 3 a) Acetylene $\left(\mathrm{C}_{2} \mathrm{H}_{2}\right)$ adsorption isotherms for all $\left(\mathbf{N H}_{2}\right)_{n}$-MOF-508 at $273 \mathrm{~K}$. The MOF508 isotherm (black) was added for comparison. b) Acetylene $\left(\mathrm{C}_{2} \mathrm{H}_{2}\right)$ adsorption isotherms for all $\left(\mathbf{N O}_{2}\right)_{n}$-MOF-508 at $273 \mathrm{~K}$. The MOF-508 isotherm (black) was added for comparison. c) Acetylene $\left(\mathrm{C}_{2} \mathrm{H}_{2}\right)$ gate opening (green filled circle), predicted gate opening (light green filled circle) and closing (green empty circle) pressure for all ( $\left.\mathbf{N H}_{2}\right)_{n}$-MOF-508 at $273 \mathrm{~K}$. Total capacity (orange filled square) as a function of mol\% of $-\mathbf{N H}_{2}$ in MOF-508 if reached below $100 \mathrm{kPa} . \mathrm{d}$ ) Acetylene $\left(\mathrm{C}_{2} \mathrm{H}_{2}\right)$ gate opening (green filled circle) and closing (green, empty circle) pressure for all $\left(\mathbf{N O}_{2}\right)_{n}$-MOF-508 at $273 \mathrm{~K}$. Total capacity (orange filled square) as a function of mol\% of NO2 in MOF-508 if reached below $100 \mathrm{kPa}$.

Fig. 4 | Predicted gate a) opening and b) closing pressures of MOF-508 and ( $\left.\mathbf{N H}_{2}\right)_{n}-\mathbf{M O F}-508$ as a function of temperature. Gray square shows the best region for practical temperature and pressure use conditions for acetylene gas storage (temperature of 273-310 K and pressure of 70$160 \mathrm{kPa})$. 


\section{Figures}
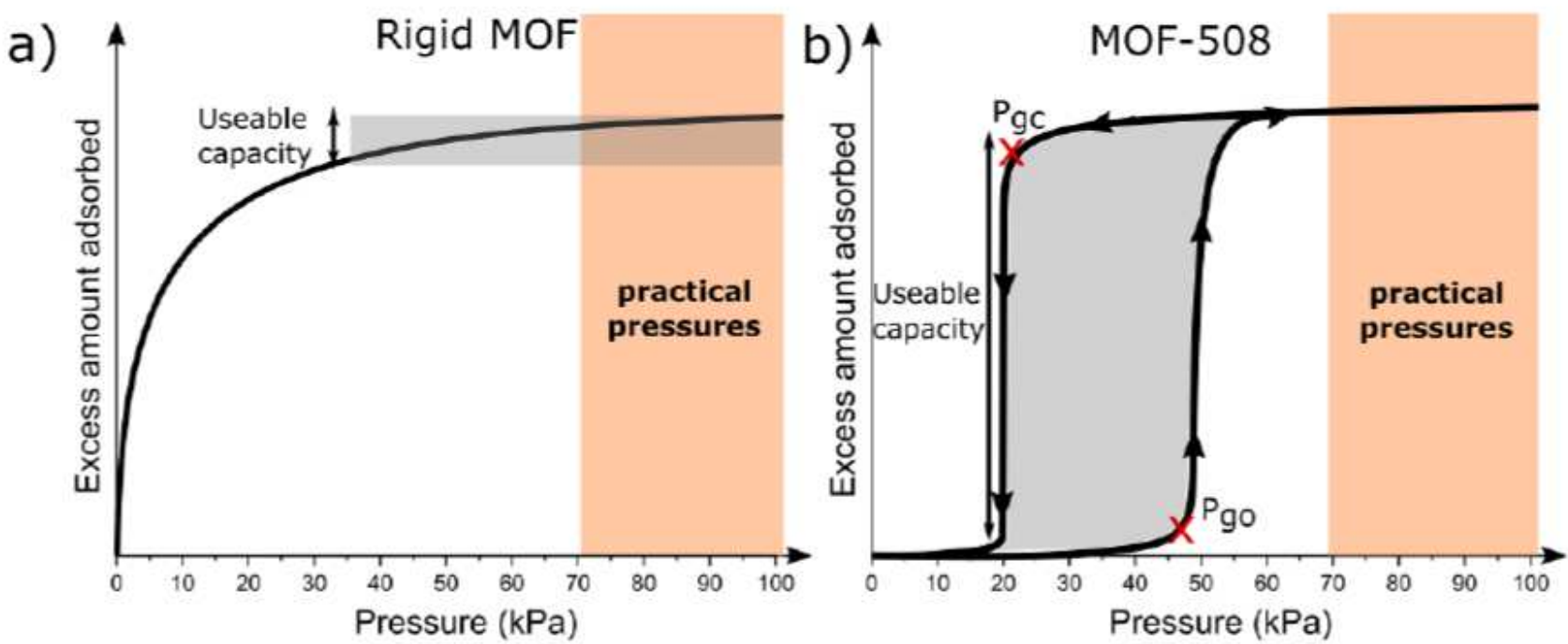

c)

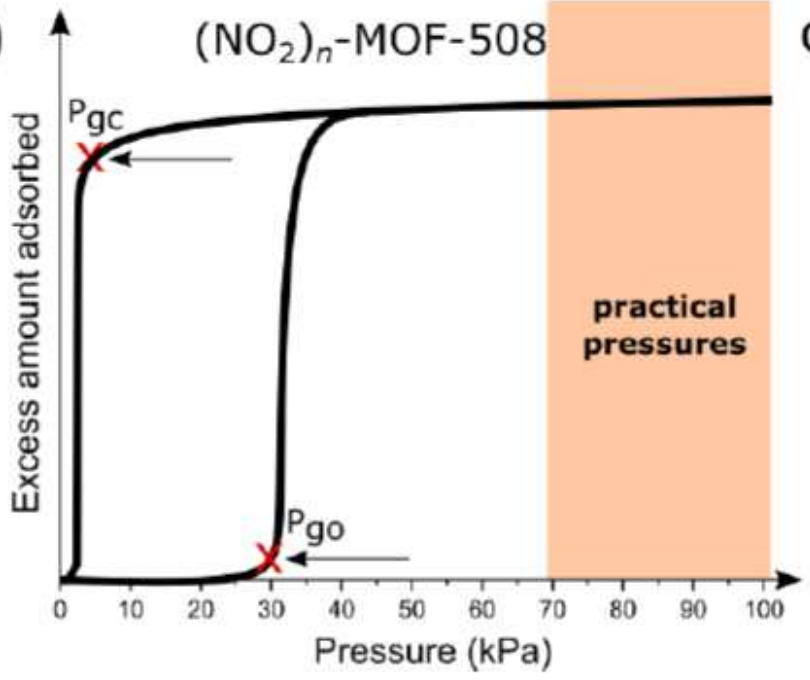

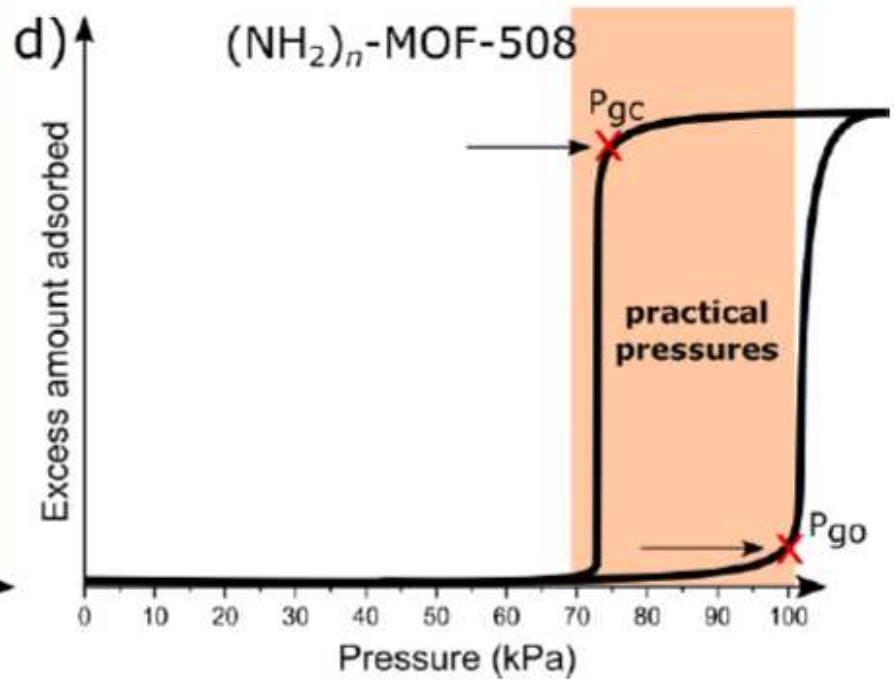

Figure 1

Comparison of acetylene gas sorption profiles and usable capacity in the pressure range of $0-100 \mathrm{kPa}$ for a) a rigid material showing a type I Langmuir isotherm, b) flexible interdigitated MOF-508 showing a $\mathrm{S}$-shape isotherm with a gate-opening pressure ( $\mathrm{Pgo})$ and a gate closing pressure $(\mathrm{Pgc})$. The orange area represents the targeted mild condition range (70-120 kPa) for acetylene uses. The functionalization of MOF-508 with - NO2 or - NH2 leads to a shift in the gate pressure to c) lower pressure or d) higher pressure range, respectively. 
a)
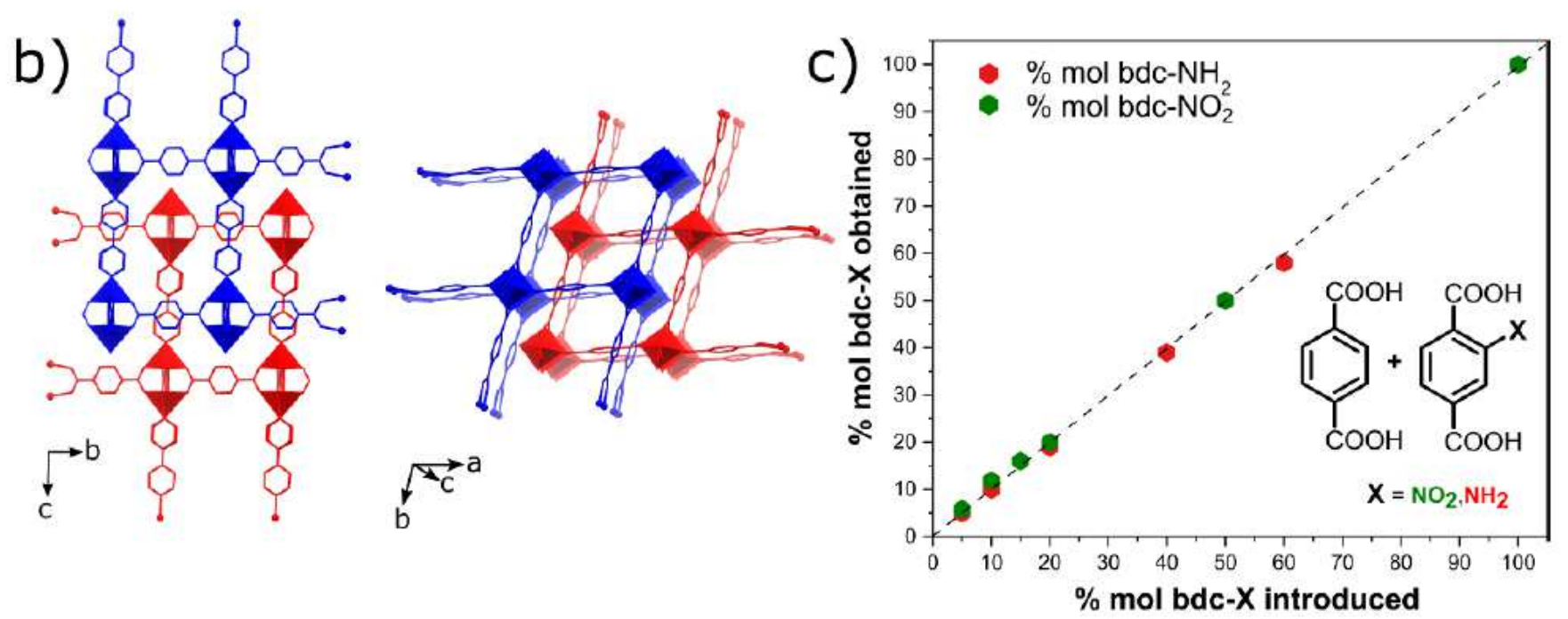

Figure 2

a) Synthetic scheme of (X)n-MOF-508 materials. b) (Left) crystal structure of activated MOF-508 along the $b$ axis and (right) crystal structure of activated MOF-508 along the $c$ axis showing a pillar ligand connecting the 2D layers. c) Molar percentage of the bdc-X linker within the material obtained as a function of the molar percentage of bdc-X introduced in the reaction. The obtained ratio was estimated from the 1HNMR spectra of digested sample. 
a)

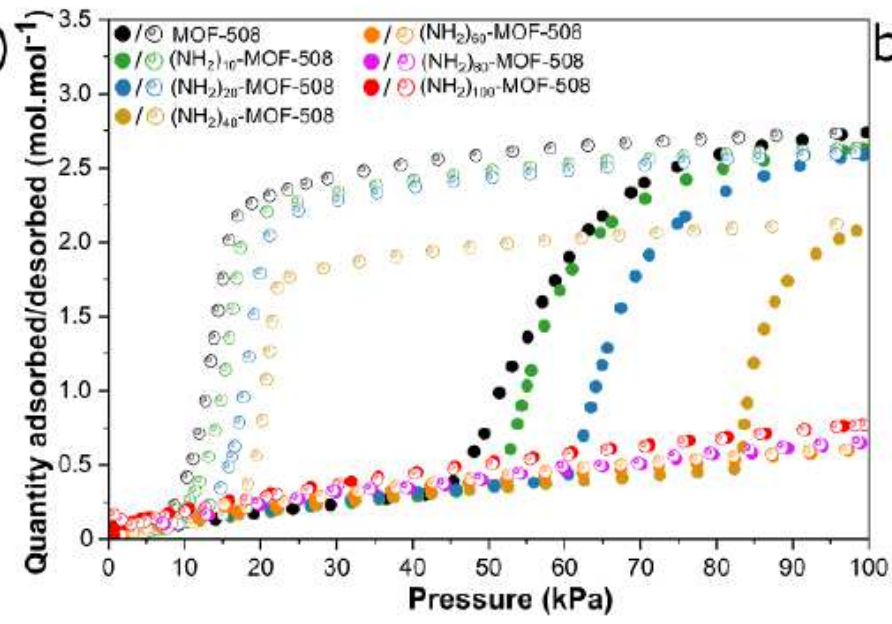

c)

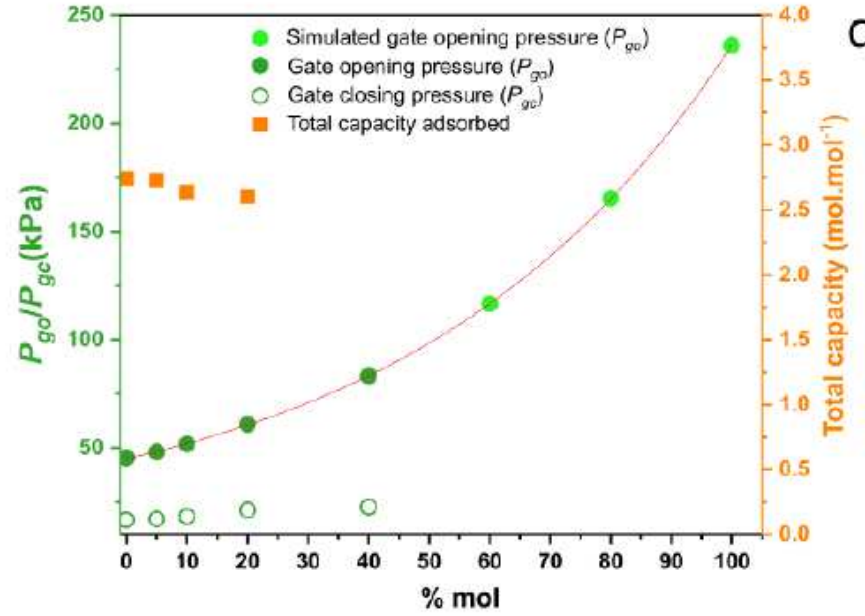

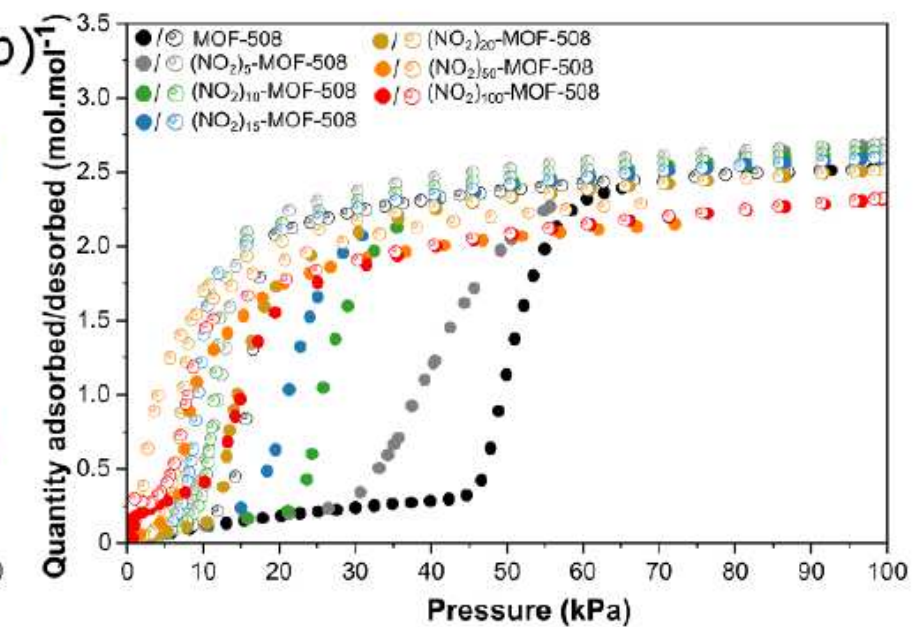

d)

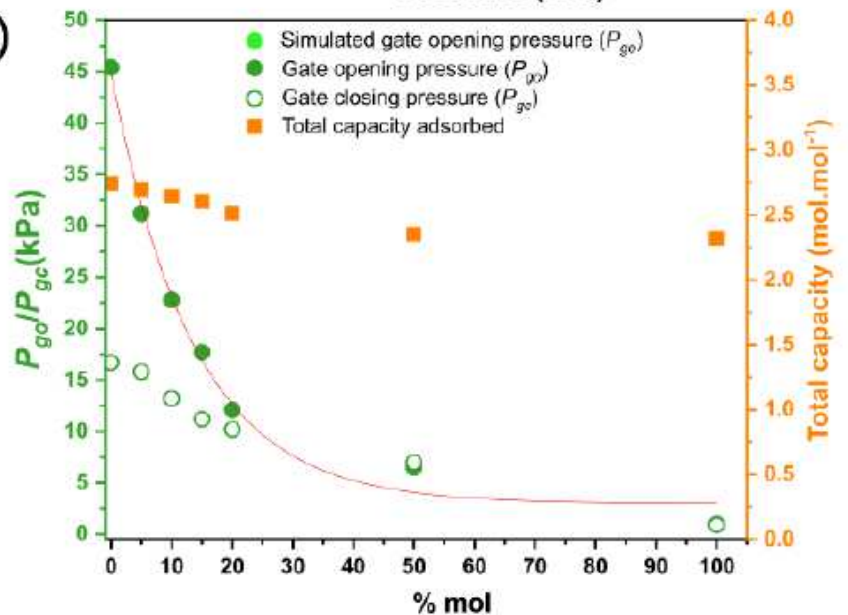

\section{Figure 3}

a) Acetylene $(\mathrm{C} 2 \mathrm{H} 2)$ adsorption isotherms for all $(\mathrm{NH} 2) n-M O F-508$ at $273 \mathrm{~K}$. The MOF-508 isotherm (black) was added for comparison. b) Acetylene $(\mathrm{C} 2 \mathrm{H} 2)$ adsorption isotherms for all (NO2)n-MOF-508 at $273 \mathrm{~K}$. The MOF-508 isotherm (black) was added for comparison. c) Acetylene $(\mathrm{C} 2 \mathrm{H} 2)$ gate opening (green filled circle), predicted gate opening (light green filled circle) and closing (green empty circle) pressure for all (NH2)n-MOF-508 at $273 \mathrm{~K}$. Total capacity (orange filled square) as a function of mol\% of $-\mathrm{NH} 2$ in MOF-508 if reached below $100 \mathrm{kPa}$. d) Acetylene (C2H2) gate opening (green filled circle) and closing (green, empty circle) pressure for all (NO2)n-MOF-508 at $273 \mathrm{~K}$. Total capacity (orange filled square) as a function of mol\% of - NO2 in MOF-508 if reached below $100 \mathrm{kPa}$. 

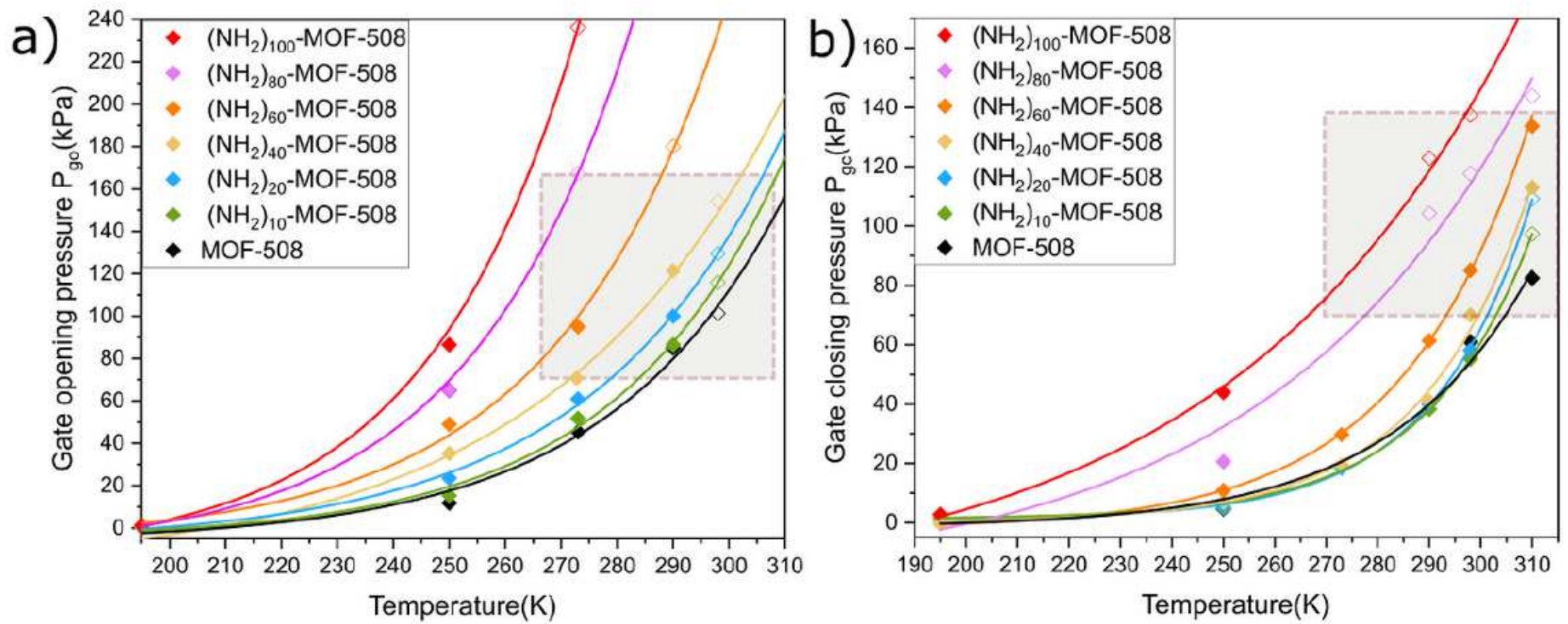

Figure 4

Predicted gate a) opening and b) closing pressures of MOF-508 and (NH2)n-MOF-508 as a function of temperature. Gray square shows the best region for practical temperature and pressure use conditions for acetylene gas storage (temperature of $273-310 \mathrm{~K}$ and pressure of $70-160 \mathrm{kPa}$ ).

\section{Supplementary Files}

This is a list of supplementary files associated with this preprint. Click to download.

- 20201104Supplementaryinformation2.pdf

- N02M0F508activated.cif

- N02MOF508assynthesized.cif

- checkcifreportmof508no2activated.pdf

- checkcifreportmof508no2assynthesized.pdf 